\title{
Changes in Intensity of Serotonin Syndrome Caused by Adverse Interaction between Monoamine Oxidase Inhibitors and Serotonin Reuptake Blockers
}

\author{
Rui Tao*,', Mary Rudacille', Gongliang Zhang',2 and Zhiyuan Ma' \\ 'Charles E. Schmidt College of Medicine, Florida Atlantic University, Boca Raton, FL, USA
}

\begin{abstract}
Drug interaction between inhibitors of monoamine oxidase (MAOls) and selective serotonin (5-hydroxytryptamine, 5-HT) reuptake (SSRIs) induces serotonin syndrome, which is usually mild but occasionally severe in intensity. However, little is known about neural mechanisms responsible for the syndrome induction and intensification. In this study, we hypothesized that the syndrome induction and intensity utilize two different but inter-related mechanisms. Serotonin syndrome is elicited by excessive 5-HT in the brain (presynaptic mechanism), whereas syndrome intensity is attributed to neural circuits involving 5- $\mathrm{HT}_{2 \mathrm{~A}}$ and NMDA receptors (postsynaptic mechanism). To test this hypothesis, basal 5-HT efflux and postsynaptic circuits were pharmacologically altered in rats by once daily pretreatment of the MAOI clorgyline for 3, 6, or 13 days. Syndrome intensity was estimated by measuring 5-HT efflux, neuromuscular activity, and body-core temperature in response to challenge injection of clorgyline combined with the SSRI paroxetine. Results showed that the onset of serotonin syndrome is caused by $5-\mathrm{HT}$ efflux exceeding 10 -fold above baseline, confirming the presynaptic hypothesis. The neuromuscular and body-core temperature abnormalities, which were otherwise mild in drug-naive rats, were significantly intensified to a severe level in rats pretreated with daily clorgyline for 3 and 6 days but not in rats pretreated for 13 days. The intensified effect was blocked by MI 00907 and MK-80 I, suggesting that variation in syndrome intensity was mediated through a 5-HT $2 \mathrm{~A}$ and NMDA receptorengaged circuit. Therefore, we concluded that pretreatments of MAOI pharmacologically alter the activity of postsynaptic circuits, which is responsible for changes in syndrome intensity.

Neuropsychopharmacology (2014) 39, 1996-2007; doi:I0.1038/npp.2014.49; published online 26 March 2014
\end{abstract}

\section{INTRODUCTION}

- Neural mechanisms for serotonin syndrome induction are different from the intensification.

- The syndrome induction is dependent on 5HT levels accumulated extracellularly.

- The syndrome intensification depends on the responsivity of postsynaptic $5-\mathrm{HT}_{2 \mathrm{~A}}$ receptors.

The first incident of adverse interaction of serotonin (5-hydroxytryptamine, 5-HT) drugs was reported nearly 60 years ago in a patient taking the monoamine oxidase inhibitor (MAOI) iproniazid in addition to the narcotic pain reliever meperidine for pulmonary tuberculosis treatment

*Correspondence: Dr R Tao, Charles E. Schmidt College of Medicine, Florida Atlantic University, 777 Glades Road, Boca Raton, FL 3343I, USA, Tel: + I 850561297 07|3, Fax: + I 8505612972221 ,

E-mail: rtao@fau.edu

${ }^{2}$ Current address: Department of Physiology, College of Basic Medical Science, Anhui Medical University, 81 Meishan Road, Hefei, Anhui 230032, China.

Received 30 October 2013; revised 15 February 2014; accepted 17 February 2014; accepted article preview online 28 February 2014
(Mitchell, 1955). Similar reports about 5-HT drug incidents have been increasing for the last two decades because of widespread use of selective serotonin reuptake inhibitors (SSRIs). Affected patients exhibit a wide array of symptoms, collectively called serotonin syndrome (Mason et al, 2000; Bucaretchi et al, 2009; Woytowish and Maynor, 2013). Clinically, specific guidelines have been developed for the syndrome prevention, prompt diagnosis, and emergency treatment (Sternbach, 2003; Nelson et al, 2007; Grady and Stahl, 2012). The syndrome intensity can be mild or severe. Whereas most cases are mild and resolve spontaneously, severe syndrome is life-threatening (Boyer and Shannon, 2005; Pedavally et al, 2013). Therefore, it is important to investigate the mechanisms underlying differential intensity of the syndrome so that effective measures can be developed to prevent death or minimize risk.

To address this, we utilized rats as an animal model to investigate neural mechanisms underlying the syndrome caused by toxic interaction between MAOIs and SSRIs. We proposed that the time course of serotonin syndrome includes syndrome induction followed by intensification. Whereas the syndrome induction is attributed to excessive 5-HT efflux (presynaptic mechanisms), the syndrome intensity is dependent on activity of postsynaptic circuits 
involving 5- $\mathrm{HT}_{2 \mathrm{~A}}$ and $\mathrm{NMDA}$ receptors (postsynaptic mechanism). It has been demonstrated in previous studies that activity of postsynaptic neural circuits can be pharmacologically altered following pretreatment with serotonergic drugs (Freo et al, 2010; Cai et al, 2013). Thus, if our hypothesis that postsynaptic mechanisms are responsible for the syndrome intensity were valid, there would be a difference between drug-naive and serotonergic drug-pretreated animals. Experiments designed to test these hypotheses were carried out from three aspects. First, we tested whether the syndrome intensity is dependent on days of serotonergic pretreatment. Animals were pre-exposed to the MAOI clorgyline (CLG) once daily for 3, 6, and 13 days. The CLG dose used in this study was $2 \mathrm{mg} / \mathrm{kg}$, presumably causing a $96-97 \%$ reduction in MAO-A activity and 5-8\% reduction in MAO-B activity (Finberg et al, 1993). On the next day of the last CLG pretreatment, syndrome intensity was determined by characterizing changes in brain 5-HT, neuromuscular behavior, autonomic function (that is, bodycore temperature), and EEG bursts in response to challenge injection of $2 \mathrm{mg} / \mathrm{kg}$ CLG combined with $15 \mathrm{mg} / \mathrm{kg}$ paroxetine (PRX). Second, we investigated whether the syndrome intensity is dependent on doses of drug challenge. In patients, the dose that molecularly affects $\sim 80 \% 5-\mathrm{HT}$ transporters in the brain is the minimum dose for PRX to produce therapeutic effects (Meyer et al, 2004; Ruhe et al, 2009). In rodents, it was estimated that $60-80 \%$ transporter occupancy requires $0.27 \mathrm{mg} / \mathrm{kg}$ of $\mathrm{PRX}$, and over $80 \%$ occupancy requires $1.1 \mathrm{mg} / \mathrm{kg}$ of PRX (Kreilgaard et al, 2008). Thus, according to a level of transporter occupancy, the PRX dose can be classified into either a minimum therapeutic dose, a maximum therapeutic dose, or an overdose. After comparing with available preclinical data (Romero et al, 1996; Beyer et al, 2002), we chose to use 1, 5, and $15 \mathrm{mg} / \mathrm{kg}$ PRX for examining the minimum therapeutic dose, maximum therapeutic dose, and drug overdose, respectively. Lastly, we determined whether the intensified syndrome is able to be pharmacologically alleviated, such as using $5-\mathrm{HT}_{2 \mathrm{~A}}$ and NMDA receptor antagonists. This is because we and others demonstrated previously that 5- $\mathrm{HT}_{2 \mathrm{~A}}$ and NMDA receptors are the components of postsynaptic circuits responsible for serotonin syndrome (Nisijima et al, 2001; Ma et al, 2008). In the present study, the selective $5-\mathrm{HT}_{2 \mathrm{~A}}$ receptor antagonist M100907 and NMDA receptor antagonist $\mathrm{MK}-801$ were utilized to test such possibility.

\section{MATERIALS AND METHODS}

\section{Animals}

Adult male Sprague-Dawley rats purchased from Charles River Laboratories (Raleigh, NC, USA) were housed in pairs under a 12-h light/dark cycle (lights on 0700 hours) in a temperature- and humidity-controlled facility. Animals were allowed to access food and water ad libitum. Animal use procedures were in strict accordance with the NIH Guide for the Care and Use of Laboratory Animals and were approved by the Florida Atlantic University-Institutional Animal Care and Use Committees (FAU-IACUC). All efforts were made to reduce the number of animals used and their suffering.

\section{Chemicals and Drug Administration}

CLG (N-methyl-N-propargyl-3-(2,4-dichlorophenoxy) propylamine hydrochloride; Sigma-Aldrich, St Louis, MO, USA) and (+)-MK-801 maleate (Tocris, Ellisville, MO, USA) were dissolved in isotonic saline. PRX (US Pharmacopeia, Rockville, MD, USA) and M100907 (kindly provided by NIH Drug Supply Program) were suspended in water. Drug solutions were prepared immediately before experiments and injected in a constant volume of $1 \mathrm{ml} / \mathrm{kg}$ body weight. Note that CLG dose of $2 \mathrm{mg} / \mathrm{kg}$ used in this study was based on its effectiveness in induction of serotonin syndrome described in previous investigations (Shioda et al, 2004; Ma et al, 2008).

\section{Protocol and Rationale for Pre-exposure to CLG}

Initial experiments were carried out in drug-naive animals injected with CLG (2 mg/kg, s.c.) combined with PRX ( $15 \mathrm{mg} / \mathrm{kg}$, i.p.). To further estimate whether history of preexposure to serotonergic drugs would alter the intensity of serotonin syndrome, animals in other sets of experiments were pretreated with CLG $(2 \mathrm{mg} / \mathrm{kg}$, once daily) for consecutive 3, 6, and 13 days. Control groups were treated with saline (SAL; $0.9 \% \mathrm{NaCl}$ at $1 \mathrm{ml} / \mathrm{kg}$, once daily) following the same schedule. The symptom measurements in response to the challenge injection (that is, CLG + PRX) were carried out on the next day after the last CLG preexposure (that is, days 4, 7, and 14). For the control groups, it was noted that rats pretreated with SAL for 3, 6, or 13 days showed the same intensity of symptoms in response to the challenge injection of CLG + veh, and thereby data from all control animals from different day groups were pooled together to serve as a general control.

To evaluate the PRX dose-dependency, rats receiving CLG for 3 days ( $2 \mathrm{mg} / \mathrm{kg}$, s.c., once daily) were examined on day 4 in response to challenge injection of 1,5 , or $15 \mathrm{mg} / \mathrm{kg}$ PRX in combination with $2 \mathrm{mg} / \mathrm{kg}$ CLG. Control animals were also pretreated with CLG for 3 days but challenged with CLG + veh on day 4. To reveal neural mechanisms involving $5-\mathrm{HT}_{2 \mathrm{~A}}$ and NMDA receptors, M100907 at $2 \mathrm{mg} / \mathrm{kg}$ (s.c.) or $\mathrm{MK}-801$ at $0.25 \mathrm{mg} / \mathrm{kg}$ (s.c.) was injected $30 \mathrm{~min}$ before challenge injection of $2 \mathrm{mg} / \mathrm{kg}$ CLG combined with $15 \mathrm{mg} / \mathrm{kg}$ PRX. Control animals for this set of experiments were administered with $1 \mathrm{ml} / \mathrm{kg} 0.9 \% \mathrm{NaCl} 30 \mathrm{~min}$ before the challenge injection of CLG + PRX.

\section{5-HT Assay}

In vivo microdialysis was used to reveal the relationship between excessive 5-HT in the brain and intensity of serotonin syndrome in response to drug adverse interaction. Rats were anesthetized by a combination of xylazine ( $4 \mathrm{mg}$ / $\mathrm{kg}$ i.p.) and ketamine ( $80 \mathrm{mg} / \mathrm{kg}$ i.p.) and then mounted in a Kopf stereotaxic frame in a flat skull position. Guide cannulae were implanted, targeting towards the prefrontal cortex (PFC; stereotaxic coordinates at $\mathrm{AP}+3.3 \mathrm{~mm}$ relative to the bregma, $\mathrm{ML} 0.8 \mathrm{~mm}$ to the midline, DV $4.5 \mathrm{~mm}$ to the skull surface), and preoptic/anterior hypothalamus (POA; AP 1.1 relative to the bregma, ML $0.9 \mathrm{~mm}, \mathrm{DV}-9.2 \mathrm{~mm}$ ). After surgery, rats were allowed to recover for 1 week before experiments. 
One day before microdialysis, the rats were briefly anesthetized with isoflurane for probe insertion. I-shaped microdialysis probes (molecular weight cutoff: $18 \mathrm{kD}$ ) were inserted through the guide cannulae targeting to the PFC $(2.0 \mathrm{~mm}$ in length for the exchange surface) and POA $(1.0 \mathrm{~mm})$ and then secured in place with dental cement. The probe inlets were attached to a perfusion line from Raturn system (Bioanalytical System, W. Lafayett, IN), and infused with the artificial cerebrospinal fluid (aCSF; containing $140 \mathrm{mM} \mathrm{NaCl}, 3 \mathrm{mM} \mathrm{KCl}, 1.5 \mathrm{mM} \mathrm{CaCl}, 1 \mathrm{mM} \mathrm{MgCl} 2$, $0.25 \mathrm{mM} \mathrm{NaH}_{2} \mathrm{PO}_{4}$, and $1.0 \mathrm{mM} \mathrm{Na}_{2} \mathrm{HPO}_{4} ; \mathrm{pH}$ : 7.4) at a flow rate of $1 \mu \mathrm{l} / \mathrm{min}$. Next day, two dialysate samples were collected to obtain basal values before administration of drugs, followed by six drug-response samples at 1-h intervals.

5-HT concentration was determined by HPLC-electrochemical detection (HTEC-500; EICOM, Japan) with a CMA/ 200 refrigerated microsampler (CMA/Microdialysis, Stockholm, Sweden). A reverse-phase column $(150 \times 1 \mathrm{~mm}$ i.d., packed with a TSK gel ODS- 80 TM, $5 \mu \mathrm{m}$ particle size) was used for 5-HT separation. The composition of mobile phase was $0.1 \mathrm{M}$ phosphate buffer ( $\mathrm{pH}$ 6.0) consisting of $1 \%$ methanol, $500 \mathrm{mg} / \mathrm{l}$ sodium-1-octanesulfonate, and $50 \mathrm{mg} / \mathrm{l}$ ethylene diamine-tetracetic acid. The flow rate was $500 \mu \mathrm{l} /$ min. The potential set on the graphite electrode was $+450 \mathrm{mV}$ (relative to $\mathrm{Ag} / \mathrm{AgCl}$ reference electrode).

Upon completion of an experiment, the rats were deeply anesthetized with pentobarbital $(100 \mathrm{mg} / \mathrm{kg}$, i.p.). The probe was infused with a $2 \%$ fast green dye for $10 \mathrm{~min}$. The animals were then decapitated and their brains were removed, frozen in $-80^{\circ} \mathrm{C}$, and sliced freehand with a razor blade. The probe location was visually inspected by comparison to the rat brain atlas (Paxinos and Watson, 1998). Data were excluded from analysis when the probes were located outside the target boundary.

\section{Nonparametric Evaluation of Syndrome Intensity}

Animals were assigned into either drug-naive or chronic CLG groups as illustrated in Table 1. In the naive groups, no pretreatment was given to animals. In chronic CLG groups, pretreatment was carried out through once daily exposure to CLG $(2 \mathrm{mg} / \mathrm{kg}$, s.c.; experimental groups) or SAL $(0.9 \%$ $\mathrm{NaCl}$ at a volume of $1 \mathrm{ml} / \mathrm{kg}$ in body weight; control groups). On the experiment day, animals were transferred to a Plexiglas cylinder ( $46 \mathrm{~cm}$ high, $20 \mathrm{~cm}$ diameter) and allowed to habituate for $2 \mathrm{~h}$ before challenge injection of CLG combined with PRX. Syndrome intensity was assessed by trained observers blind to drug injection. Nonparametric symptoms including forepaw treading, tremor, hindlimb abduction, Straub's tail, and immobility were identified and scored at four levels as described in our previous study (Ma et al, 2008). The rating was performed in the time period between 2 and $3 \mathrm{~h}$ after challenge injection, during which the response reached a maximum level. Briefly, each symptom was rated on a 4-level scale: absence (level 0), mild (level 1), moderate (level 2), and severe (level 3). Theoretically, the maximum behavioral score would be 15 if an animal had most severe symptoms of serotonin syndrome.

\section{Measurement of Body-Core Temperature $\left(T_{\text {cor }}\right)$}

$T_{\text {cor }}$ was measured by inserting into the rectum a flexible, 4.6- $\mathrm{cm}$ thermoprobe connected to a digital thermometer (Traceable, Fisher Scientific; Pittsburgh, PA, USA). Recordings included two pre-challenge baselines and six or seven post-challenge measurements at 1-h intervals. Changes were categorized into hyperthermia, normothermia, and hypothermia. Hyperthermia is defined as an increase in $T_{\text {cor }}$ by over $2{ }^{\circ} \mathrm{C}$ above its baseline, whereas hypothermia is a reduction by over $1{ }^{\circ} \mathrm{C}$ below its baseline. Changes between +2 and $-1{ }^{\circ} \mathrm{C}$ are considered as normothermia.

\section{EEG Recording and Head Shaking Behavior}

Intensity of head shaking behavior was estimated by counting numbers of EEG bursts in a given time period. EEG electrodes were pre-implanted before experiments. Briefly, rats were anesthetized with a combination of xylazine $(4 \mathrm{mg} / \mathrm{kg}$ i.p.) and ketamine $(80 \mathrm{mg} / \mathrm{kg}$ i.p.). Two stainless steel electrodes were anchored on the skull over the frontal cortex (AP $+2 \mathrm{~mm}$ relative to the bregma, $\mathrm{ML} \pm 2 \mathrm{~mm}$ to the midline) as positive and reference electrodes for surface EEG recording. A third electrode was implanted on the occipital bone over the cerebellum to serve as the negative electrode. After surgery, rats were housed individually and allowed a week for recovery. One day before EEG recording, animals were placed in the recording chamber shielded with a metal mesh for blocking electromagnetic interference from surrounding environment. The following day, recording began with baseline measurements and then postchallenge injection recordings were made.

Electroencephalograms were analyzed off-line. Since the head shaking behavior was most obvious at the beginning of the syndrome, EEG analysis was therefore performed in the time frame of first 60 min after CLG + PRX injection. Head shake was characteristically correlated to the EEG burst

Table I Experimental Groups, Pretreatment, and Drug Challenge Protocol

\begin{tabular}{|c|c|c|c|c|c|c|c|}
\hline \multirow[b]{2}{*}{ Pretreatment } & \multicolumn{3}{|c|}{ Naive } & \multicolumn{4}{|c|}{ Chronic CLG } \\
\hline & No & No & No & SAL 3-13 days & $\mathrm{CLG} \times 3$ days & $\mathrm{CLG} \times 6$ days & $C L G \times 13$ days \\
\hline Challenge with & $\mathrm{SAL}+$ veh & $\mathrm{SAL}+\mathrm{PRX}$ & $C L G+P R X$ & $\mathrm{CLG}+$ veh & $C L G+P R X$ & $C L G+P R X$ & $C L G+P R X$ \\
\hline
\end{tabular}

Abbreviations: CLG, clorgyline; PRX, paroxetine; SAL, saline; Veh, vehical.

$\mathrm{CLG}$ at a dose of $2 \mathrm{mg} / \mathrm{kg}$, s.c.

$\mathrm{PRX}$ at $15 \mathrm{mg} / \mathrm{kg}$, i.p.

$\mathrm{SAL}$ and veh at $1 \mathrm{ml} / \mathrm{kg}$, s.c. 
showing sudden high spikes of electrical activity (usually more than $500 \mu \mathrm{V}$ arising from the baseline of $50-100 \mu \mathrm{V}$ ), which could be reliably counted.

\section{Statistical Analysis}

Data are expressed as means \pm SEM. Repeated measures ANOVA followed by the post hoc Scheffe test were used to determine statistical difference between groups of microdialysis, EEG recordings, and changes in $T_{\text {cor }}$. Note that Mann-Whitney $U$-test or Kruskal-Wallis followed by the post hoc Dunn's test was employed to examine nonparametric data. In some cases, the paired $t$-test was used if appropriate. Statistical significance was achieved only when $P$-value was less than 0.05 .

\section{RESULTS}

\section{Experiment 1: Changes in Extracellular 5-HT in Response to Drug Adverse Interaction}

In drug-naive rats, basal concentrations of extracellular 5 -HT were $1.2 \pm 0.4 \mathrm{pg} / \mathrm{sample}$ (uncorrected for probe recovery) in the PFC. Increases in 5-HT efflux (calculated as fold above baseline) were 0.2 -fold in response to $2 \mathrm{mg} / \mathrm{kg}$ CLG injection (Figure 1a left panel; CLG + veh group; $N=7$ ) and twofold following $15 \mathrm{mg} / \mathrm{kg}$ PRX injection (Figure 1a left panel; SAL + PRX group; $N=6$ ). Compared with controls (ie, SAL + veh group, $N=5$ ), the elevation was significant $\left(\mathrm{CLG}, \mathrm{F}_{(1,10)}=5.806, P=0.0393 ; \mathrm{PRX}, \mathrm{F}_{(1,9)}=8.925, \quad P=\right.$ 0.0153). Remarkably, there was an 80 -fold increase in response to combined injection of CLG + PRX $\left(\mathrm{F}_{(1,7)}=27.71, P=\right.$ $0.0012 ; N=4)$. In the POA, basal $5-\mathrm{HT}$ was $0.7 \pm 0.1 \mathrm{pg} /$ sample. Injection of CLG or PRX alone caused a significant elevation in extracellular 5 -HT by 0.5 -fold and onefold, respectively (Figure 1a right panel; CLG + veh, $\mathrm{F}_{(1,11)}=$ $30.885, P=0.0002$; SAL + PRX, $\left.\mathrm{F}_{(1,10)}=12.679, P=0.0032\right)$. In contrast, there was a 60 -fold increase following combined injection of CLG + PRX $\left(\mathrm{F}_{(1,10)}=200.091, P<0.0001\right)$.

We next examined whether CLG pretreatment could alter 5-HT response to drug adverse interaction. In this study, animals were pretreated once daily with CLG for 3, 6, or 13 days in experimental groups, or saline in control groups on the same schedule. Chronic CLG pretreatments $(2 \mathrm{mg} / \mathrm{kg}$, s.c.) elevated the baseline in the PFC (chronic CLG for 4 days, $2.5 \pm 0.3 \mathrm{pg} / \mathrm{sample} ; 7$ days, $4.0 \pm 0.7 \mathrm{pg} / \mathrm{sample}$; 14 days, $4.2 \pm 0.4 \mathrm{pg} / \mathrm{sample}$ ) and POA (4 days, $2.7 \pm$ $0.4 \mathrm{pg} / \mathrm{sample} ; 7$ days, $3.6 \pm 0.5 \mathrm{pg} / \mathrm{sample}$; and 14 days, $4.7 \pm 0.5 \mathrm{pg} / \mathrm{sample})$. Taken together, it appeared to be that the baseline was gradually increased in the rank order of day $14>$ day $7>$ day 4 . A one-way ANOVA test revealed significant differences in baseline 5-HT across days $\left(\mathrm{PFC}, \mathrm{F}_{(3,12)}=8.412, P=0.0028\right.$; and $\mathrm{POA}, \mathrm{F}_{(3,12)}=16.215$, $P=0.0002)$.

Challenge injection of CLG + PRX to CLG-pretreated rats produced increases in 5-HT efflux in both the PFC and POA, similar to those of drug-naive rats. Further data analysis showed that the absolute value of 5-HT efflux remained in the range of $\sim 60-120 \mathrm{pg} / \mathrm{sample}$ in response to the challenge of CLG + PRX (see details in Supplementary Figure S1). However, because of increased basal value after daily CLG pretreatment, the fold increase relative to
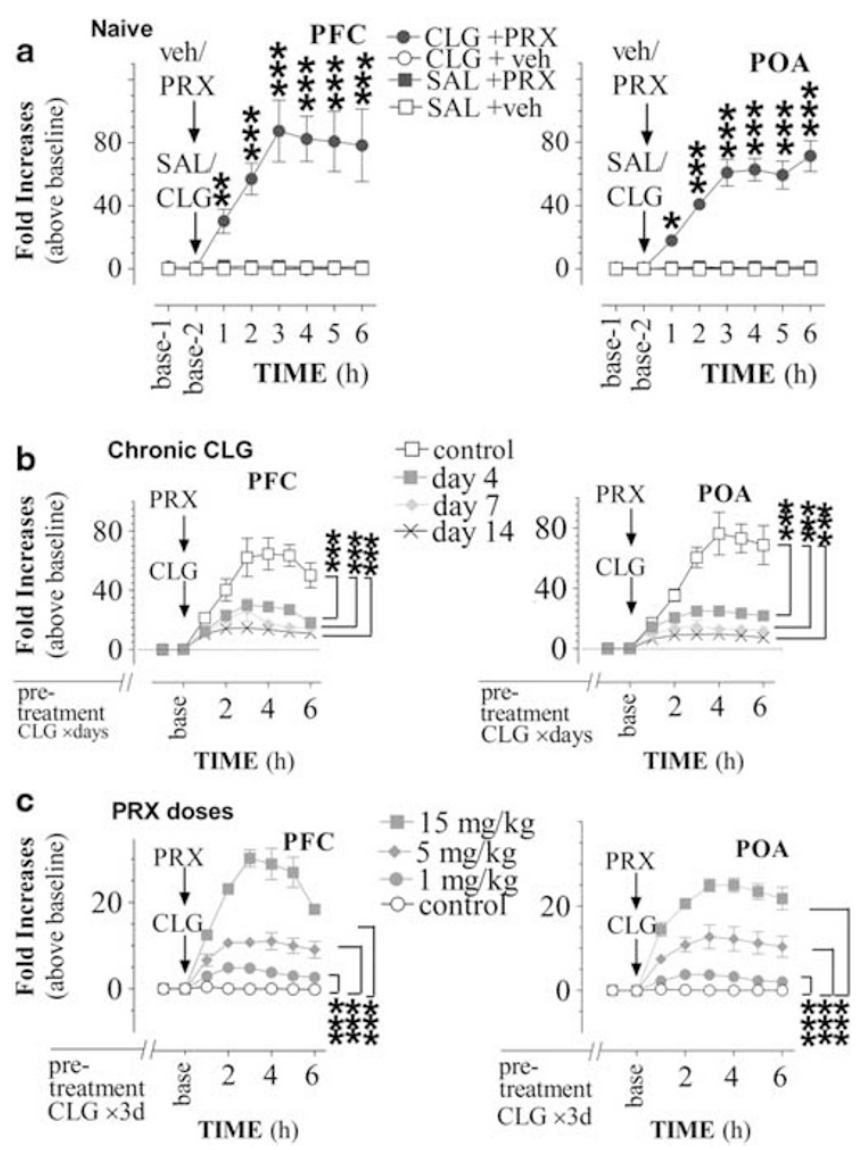

Figure I Excessive 5-hydroxytryptamine (5-HT) efflux induced by a drug interaction between paroxetine (PRX; $15 \mathrm{mg} / \mathrm{kg}$, i.p) and clorgyline (CLG; 2 mg/kg, s.c.). Data represent mean ( \pm SEM) increases in 5-HT efflux (fold above baseline), obtained from four to eight animals in each group. (a) Drug-naive rats. Compared with three control groups (groups of SAL + veh, CLG + veh, and SAL + PRX, acute injection of CLG + PRX caused an 'excessive' increase in extracellular 5-HT in the prefrontal cortex (PFC, left panel) and preoptic/anterior hypothalamus (POA, right panel). (b) Experimental rats received CLG pretreatment for 3-13 days and were examined on the next day after the last pretreatment. Control animals were pretreated with saline on the same schedule. Although challenge injection of CLG + PRX produced an excessive increase in 5-HT efflux, this effect was inversely reduced in a day-dependent manner. (c) All rats received CLG pretreatment for 3 days and were examined on day 4 . Challenge injection of CLG + PRX with PRX doses at I, 5, and $15 \mathrm{mg} / \mathrm{kg}$ produced a dose-dependent increase in extracellular 5-HT in the PFC and POA. ${ }^{*} P<0.05,{ }^{* * *} P<0.01$, and ${ }^{* * *} P<0.00$ I vs control groups, examined by repeat measures ANOVA followed by Scheffe test.

baseline was reduced in a day-dependent manner (Figure 1b; PFC, $\mathrm{F}_{(3,14)}=25.701, P<0.0001 ; \mathrm{POA}, \mathrm{F}_{(3,12)}=10.049, P=$ $0.0014)$. Specifically, compared with the 60 - to 80 -fold increase in control rats, the fold increase was reduced to 25 - to 30 -fold in the day-4 group, to $\sim 19$ - to 25 -fold in the day-7 group, and to $\sim 10$ - to 19 -fold in the day-14 group.

Next, we investigated a PRX dose-dependent effect on 5-HT efflux in the brain. As shown in Figure 1c, PRX at doses of 1,5 , and $15 \mathrm{mg} / \mathrm{kg}$ in combination with CLG caused dose-dependent increases in 5-HT efflux in the PFC $\left(\mathrm{F}_{(3,12)}=21.126, P=0.0001\right)$ and POA $\left(\mathrm{F}_{(3,12)}=102.209\right.$, $P=0.0001)$. Note that this set of experiments was carried out in rats pretreated with CLG for 3 days since the syndrome intensity was highly intensified at this time frame (see details in experiment 2). Under this condition, the 
increase in 5-HT efflux was approximately five-fold, 11-fold, and 30 -fold in response to 1,5 , and $15 \mathrm{mg} / \mathrm{kg}$, respectively, in the PFC. Similarly, the increase was up to approximately fourfold, 12 -fold, and 25-fold, respectively, in the POA.

\section{Experiment 2: Syndrome Intensity Estimated by Nonparametric Analysis}

Tremor, forepaw treading, hindlimb abduction, Straub tail, and immobility were rated on a 4-level scale (no effect $=0$; mild $=1$; moderate $=2$; severe $=3$ ). In drug-naive rats, PRX alone $(15 \mathrm{mg} / \mathrm{kg})$ had no effect on these symptoms. In addition, no behavioral syndrome was detected following CLG + PRX with the PRX dose at 1 or $5 \mathrm{mg} / \mathrm{kg}$ (each $N=5$; data not shown). When the PRX dose was increased to $15 \mathrm{mg} / \mathrm{kg}$ (Figure 2a), there was a small but significant increase in scores of tremor $(U=10.5, P=0.0262)$, forepaw treading $(U=10.5, \quad P=0.0262)$, hindlimb abduction $(U=21, P=0.2664)$, Straub tail $(U=23.8, P=0.3921)$, and immobility $(U=7, P=0.0095)$. Collectively, the rating scale was $\sim 1$, indicating a mild effect in drug-naive animals.

Next, CLG + PRX with the PRX dose of $15 \mathrm{mg} / \mathrm{kg}$ was administered to rats previously pretreated with CLG for 3, 6, or 13 days. Note that control animals were pretreated with saline $(0.9 \% \mathrm{NaCl}, 1.0 \mathrm{ml} / \mathrm{kg}$, s.c., once daily) on the same schedule (since there was no difference in the syndrome intensity among control animals, data were pooled together
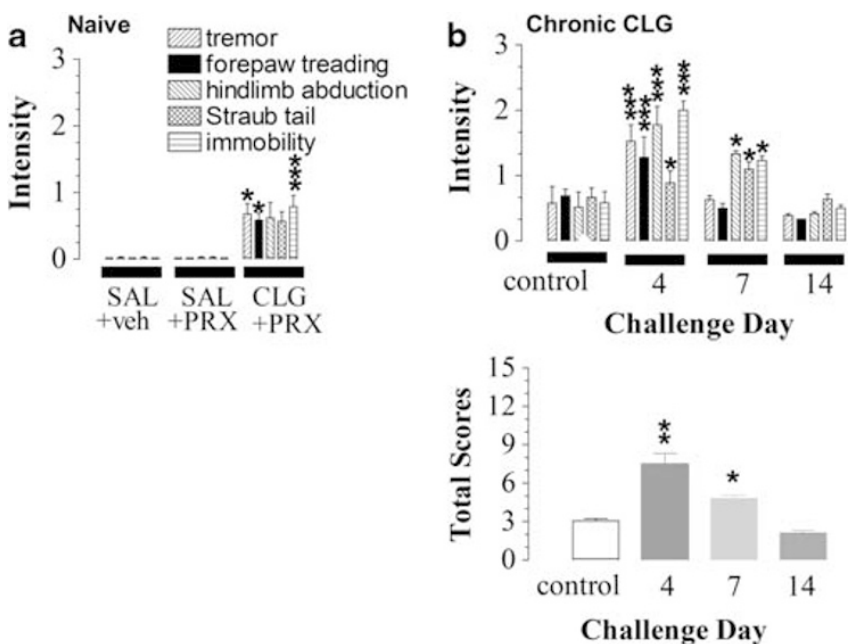

Figure 2 Intensity of behavioral serotonin syndrome induced by a drug interaction between paroxetine (PRX; $15 \mathrm{mg} / \mathrm{kg}$, i.p.) and clorgyline (CLG; $2 \mathrm{mg} / \mathrm{kg}$, s.c.). Data represent mean ( \pm SEM) intensity score. Behavioral symptoms (that is, tremor, forepaw treading, hindlimb abduction, Straub tail, and immobility) were scored on a 4-level scale: no effect $=0$, mild effect $=1$, moderate effect $=2$, and severe effect $=3$. (a) Drug-naive animals $(N=5-8)$. The $y$ axis represents the intensity of individual behaviors. PRX alone had no effect, whereas CLG + PRX produced mild effect on behavior intensity. (b) Experimental animals received daily CLG for 3-13 days $(N=5-8)$ and then were challenged on the next day with $\mathrm{CLG}+\mathrm{PRX}$ with the PRX dose of $15 \mathrm{mg} / \mathrm{kg}$. Control animals were also challenged with CLG $+P R X$. The syndrome intensity was exacerbated in animals pretreated with CLG for 3 and 6 days. In contrast, the syndrome intensity in rats receiving CLG for 13 days was not different from the control group. (b) bottom panel. The syndrome intensity was re-evaluated by summation of individual components. ${ }^{*} P<0.05,{ }^{* * *} P<0.01$, and ${ }^{*} P<0.00$ I vs respective control animals, analyzed with the MannWhitney U-test or Kruskal-Wallis nonparametric analysis followed by post hoc Dunn's test. as a general control). Compared with the control, intensity scores were significantly aggravated after daily CLG pretreatment for 3-6 days in response to CLG + PRX (Figure 2b). This conclusion was confirmed with the Mann-Whitney nonparametric analysis demonstrating significant effects of CLG pretreatments on all five components in the day 4 group (tremor, $U=4, P=0.0067$; forepaw treading, $U=2.5, P=0.0039$; hindlimb abduction, $U=4.5$, $P=0.0080$; Straub tail, $U=8, P=0.025$; immobility, $U=0$, $P=0.0015)$. The syndrome in rats previously receiving CLG for 6 days was partially aggravated, showing significant increases in three of the five components (tremor, $U=13$, $P=0.4649$; forepaw treading, $U=11, P=0.2912$; hindlimb abduction, $\mathrm{U}=5, P=0.0481$; Straub tail, $U=2, P=0.0118$; immobility, $U=4, P=0.0214)$. The syndrome in rats previously receiving CLG for 13 days was not aggravated, showing that none of the five components was significantly different from the control group (tremor, $U=24, P=$ 0.4008; forepaw treading, $U=32, P=0.9999$; hindlimb abduction, $U=30.5, \quad P=0.8748$; Straub tail, $U=22.5$, $P=0.8184$; immobility, $U=27, P=0.5995)$.

To appraise the overall response to the CLG + PRX challenge, five individual components were summed up as shown in Figure 2b bottom panel. The Kruskal-Wallis nonparametric analysis revealed significant differences in the syndrome intensity across multiple days of CLG pretreatments $\left(\mathrm{kw}_{(3,24)}=18.989, P=0.0003\right)$. Multiple comparisons among groups revealed that the syndrome severity of day- 4 and day-7 groups was significantly higher than those of other groups. Thus, most of following experiments regarding adverse interaction between CLG pre-exposure and CLG + PRX challenge were carried out on day 4 in rats receiving CLG pretreatments for 3 days.

Whether the syndrome intensity in CLG pretreatment rats was altered in a PRX dose-dependent manner was examined next. Figure 3a shows the syndrome intensity in response to

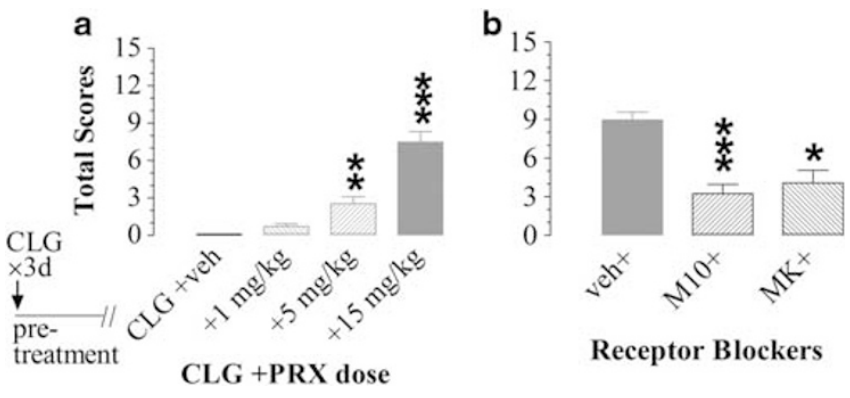

Figure 3 Paroxetine $(P R X)$ dose-dependent changes in the syndrome intensity of rats pretreated with clorgyline (CLG, $2 \mathrm{mg} / \mathrm{kg}$, s.c.) once daily for 3 days. Experiments were carried out on day 4. Data represent mean ( \pm SEM) total intensity score, obtained from five to eight animals/group. (a) Animals were challenged with CLG + veh (control), CLG + I mg/kg PRX, or CLG $+5 \mathrm{mg} / \mathrm{kg} P R X$. Note that the $15 \mathrm{mg} / \mathrm{kg}$ data are a replot of Figure $2 b$. The $y$ axis represents the mean summation of five behavioral components (tremor, forepaw treading, hindlimb abduction, Straub tail, and immobility). PRX in combination with CLG produced a dose-dependent effect on the syndrome intensity. ${ }^{* *} P<0.01$; ${ }^{* * *} P<0.001$ vs the control (CLG + veh) group. (b) Animals were injected with vehicle (veh group), 2 mg/kg Ml 00907 (Ml 0 group), or 0.25 mg/kg MK-80 I (MK group), 30 min before the challenge injection of CLG + PRX with the PRX dose at $15 \mathrm{mg} /$ $\mathrm{kg}$. Compared with the vehicle control, syndrome intensity was significantly reduced in animals pretreated with MI00907 or MK-80I. " $P<0.05$ and

${ }^{* * *} P<0.00$ I vs control (veh $+\mathrm{CLG}+\mathrm{PRX}$ ) group. 
1, 5, and $15 \mathrm{mg} / \mathrm{kg}$ PRX combined with $2 \mathrm{mg} / \mathrm{kg}$ CLG. Control group had also received daily CLG pretreatment for 3 days but were challenged with CLG + veh. Note that the $15-\mathrm{mg} / \mathrm{kg}$ PRX data were a replot of Figure 2b. PRX doses had a dose-dependent effect on the syndrome intensity $\left(\mathrm{kw}_{(3,27)}=24.258, P<0.0001\right)$. Apparently, 5 and $15 \mathrm{mg} / \mathrm{kg}$ PRX caused significant changes in the syndrome intensity score.

Next, we investigated whether the syndrome intensity was mediated through $5-\mathrm{HT}_{2 \mathrm{~A}}$ or/and NMDA receptors. Tests were carried out on day 4 in rats previously receiving daily CLG for 3 days. The $5-\mathrm{HT}_{2 \mathrm{~A}}$ receptor antagonist M100907 (2 mg/kg, s.c.) or the NMDA receptor antagonist MK-801 $(0.25 \mathrm{mg} / \mathrm{kg}$, s.c.) was injected in the experimental group, whereas vehicle was injected in the control group, $30 \mathrm{~min}$ before challenge injection of CLG + PRX with the PRX dose of $15 \mathrm{mg} / \mathrm{kg}$. As shown in Figure 3b, the behavioral scores were reduced by pretreatment of M100907 and MK-801. The conclusion was supported by nonparametric analysis indicating significant main effects of the antagonists on the syndrome intensity $\left(\mathrm{kw}_{(2,19)}=15.041\right.$, $P=0.005)$.

\section{Experiment 3: Syndrome Intensity Estimated by Changes in Body-core Temperature ( $\left.T_{\text {cor }}\right)$}

In drug-naive animals, $T_{\text {cor }}$ was slightly reduced in response to SAL + PRX (Figure 4a). Compared with controls (SAL + veh), the reduction was significant $\left(\mathrm{F}_{(1,8)}=9.278, P=\right.$ 0.0159). Interestingly, combined injection of CLG + PRX caused a similar but sustained reduction in $T_{\text {cor }}$ $\left(\mathrm{F}_{(1,8)}=10.255, P=0.0126\right)$. To further illustrate the relationship between $T_{\text {cor }}$ and drug injection, the $T_{\text {cor }}$ responses were plotted as bar graphs and displayed in the right panel. Statistical analysis reaffirmed that the reduction was significant $(\mathrm{SAL}+\mathrm{PRX}, t$-value $=8.3, P=0.0012 ; \mathrm{CLG}+$ PRX, $t$-value $=4.383, P=0.0032$ ).

Next, $T_{\text {cor }}$ response was determined in rats previously receiving daily CLG pretreatments for 3, 6, and 13 days. Control groups were treated with saline (SAL; $0.9 \% \mathrm{NaCl}$ at $1 \mathrm{ml} / \mathrm{kg}$, once daily) on the same schedule. Compared with baseline, challenge injection of CLG + PRX to control rats caused a reduction in $T_{\text {cor }}$ (Figure $4 \mathrm{~b}$ ), similar to that in drug-naive rats (Figure 4a). Interestingly, challenge injection caused an increase in the day- $4\left(\mathrm{~F}_{(1,8)}=30.047\right.$, $P=0.0006)$ and day-7 groups $\left(\mathrm{F}_{(1,8)}=70.307, P<0.0001\right)$. There was no significant difference between control and the day-14 group $\left(\mathrm{F}_{(1,8)}=0.014, P=0.9102\right)$. The maximum response was displayed in the bar graph, reaffirming significant changes in the day- $4(t$-value $=3.916, P=0.0173)$ and day-7 group ( $t$-value $=8.479, P=0.0001)$ but not in the day-14 group $(t$-value $=1.312, P=0.2308)$.

The dose-dependent effect of PRX on $T_{\text {cor }}$ was examined in rats receiving CLG pretreatments for 3 days and challenged on day 4 with CLG combined with PRX at doses of 1,5 , and $15 \mathrm{mg} / \mathrm{kg}$. Note that the data of $15-\mathrm{mg} / \mathrm{kg}$ PRX was a replot from Figure $4 \mathrm{~b}$. As shown in Figure $5, T_{\text {cor }}$ was altered to three different statuses. Specifically, CLG + PRX at the PRX doses of 1,5 , and $15 \mathrm{mg} / \mathrm{kg}$ induced hypothermia, normothermia, and hyperthermia, respectively. The one-way ANOVA analysis revealed a dose-dependent effect of PRX $\left(\mathrm{F}_{(3,24)}=31.365, P<0.0001\right)$. The bar graph

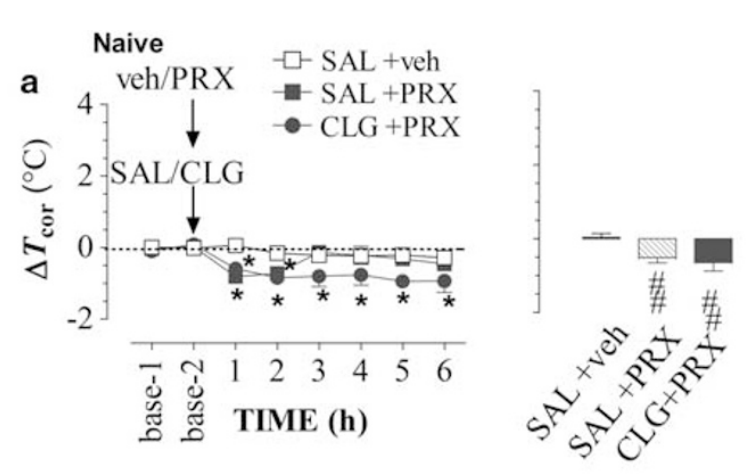

Chronic CLG

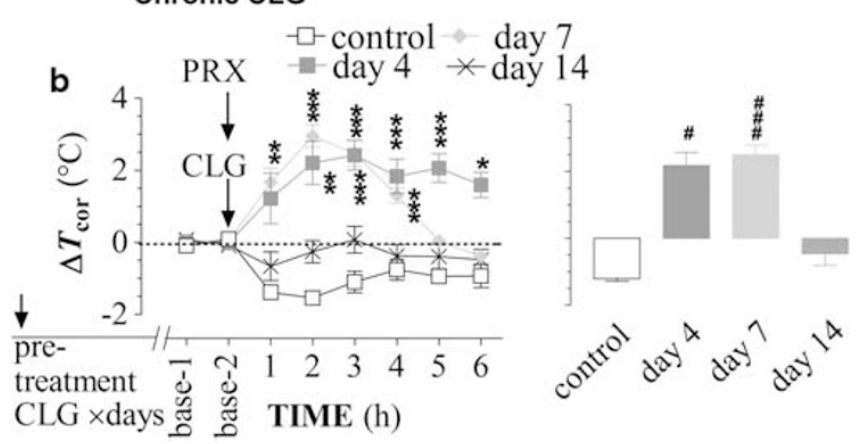

Figure 4 Body-core temperature $\left(T_{\text {cor }}\right)$ changes induced by a drug interaction between paroxetine (PRX; $15 \mathrm{mg} / \mathrm{kg}$, i.p.) and clorgyline (CLG; $2 \mathrm{mg} / \mathrm{kg}$, s.c.). $T_{\text {cor }}$ was measured at I-h intervals. Data are expressed as the mean changes in $T_{\text {cor }}( \pm S E M)$, obtained from five rats/group. (a) Drugnaive animals. $T_{\text {cor }}$ was reduced in response to either $P R X$ alone or CLG + PRX. (b) Rats received daily CLG pretreatment for 3, 6, and 13 days. The challenge injection of $C L G+P R X$ caused hyperthermia in animals pretreated with CLG for 3 and 6 days, but not in rats pretreated with CLG for 13 days. ${ }^{*} P<0.05,{ }^{* *} P<0.01$, and ${ }^{* * *} P<0.001$ vs control group, examined by repeated measures ANOVA followed by Scheffe test; ${ }^{\#} P<0.05,{ }^{\# \#} P<0.01$, and ${ }^{\# \# \#} P<0.00$ I vs respective baseline using paired t-test.

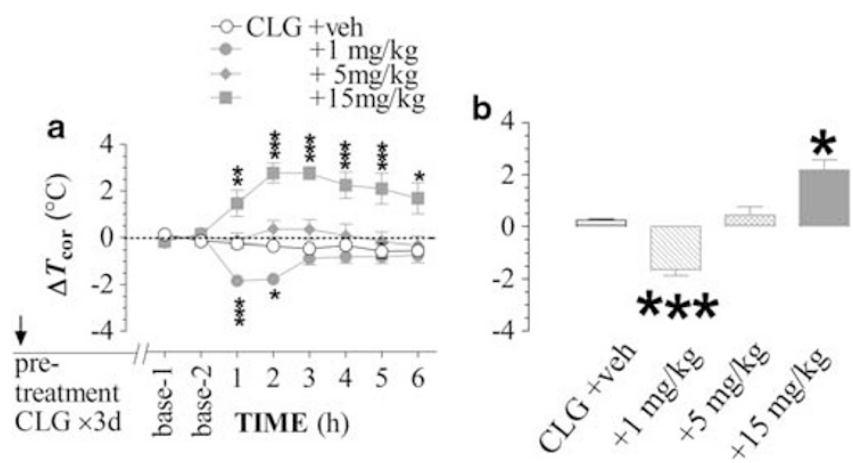

Figure 5 Paroxetine $(P R X)$ dose-dependent changes in body-core temperature ( $\left.T_{\text {cor }}\right)$ of rats pretreated with clorgyline (CLG, $2 \mathrm{mg} / \mathrm{kg}$, s.c.) once daily for 3 days. Data are expressed as the mean changes in $T_{\text {cor }}$ ( \pm SEM), obtained from 5-8 rats/group. Rats received daily CLG once daily for 3 days and were examined on day 4 in response to challenge injection of CLG + PRX with the PRX doses at 0 (veh), I, or $5 \mathrm{mg} / \mathrm{kg}$. Note that the I5-mg/kg data are a replot of Figure 4b. (a) Time-course of a PRX dosedependent change in $T_{\text {cor. }}$ (b) $P R X$ at $\mathrm{I}, 5$, and $15 \mathrm{mg} / \mathrm{kg}$ induced hypothermia, normothermia, and hyperthermia, respectively. ${ }^{*} P<0.05$ and ** $P<0.00$ I vs respective controls. 

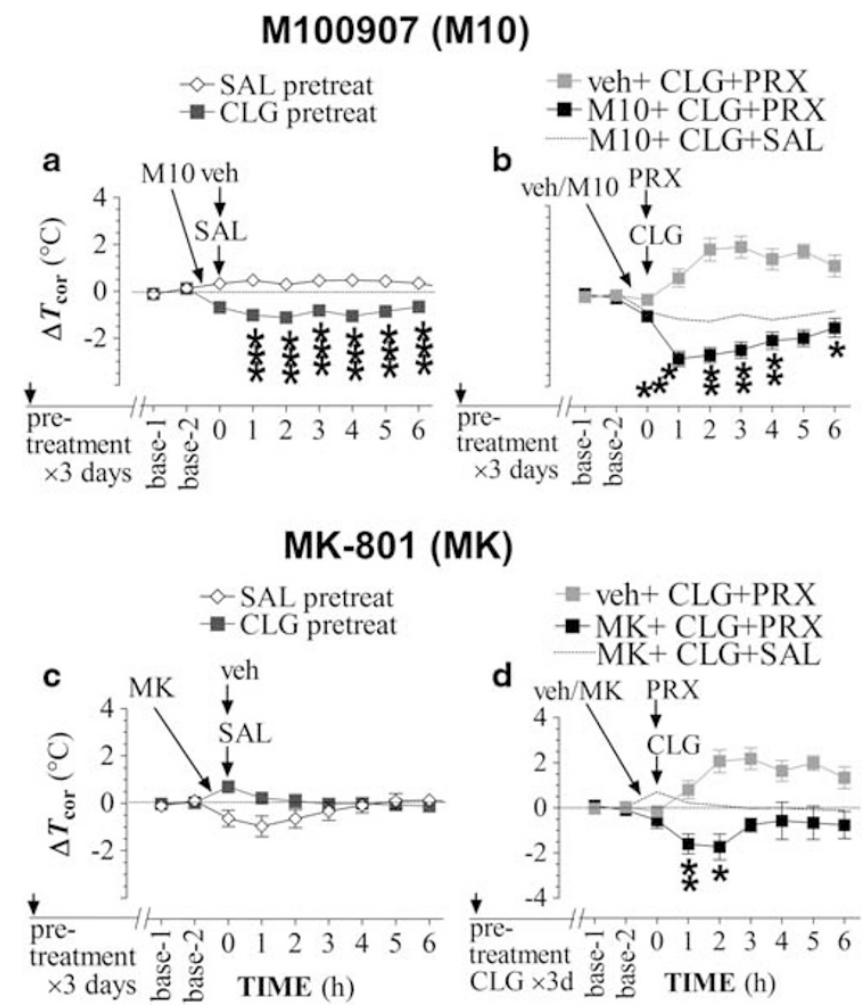

Figure 6 Effect of receptor blockers on body-core temperature $\left(T_{\text {cor }}\right)$ of rats pretreated with clorgyline (CLG, $2 \mathrm{mg} / \mathrm{kg}$, s.c.) daily for 3 days. Data are expressed as the mean changes of $T_{\text {cor }} \pm$ SEM. (a) Rats ( $N=5 /$ group) received either daily SAL ( $\mathrm{ml} / \mathrm{kg} 0.9 \% \mathrm{NaCl}$, s.c.) or daily CLG for 3 days and were examined on day 4. MI 00907 (MI0; 2 mg/kg, s.c.) injected $30 \mathrm{~min}$ before challenge injection of $\mathrm{SAL}+$ veh caused a significant reduction in CLG-pretreated rats. ${ }^{* * *} P<0.001$ vs SAL-pretreated rats. (b) All rats received daily CLG for 3 days and were examined on day 4 . Vehicle (veh group; $N=4$ ) or $2-\mathrm{mg} / \mathrm{kg}$ MI00907 (MIO group; $N=8$ ) was injected $30 \mathrm{~min}$ before challenge injection of CLG + PRX with the PRX dose at $15 \mathrm{mg} / \mathrm{kg}$. Compared with the veh control, MI00907 (MIO) blocked CLG + PRX-induced hyperthermia. Compared with the MIO + CLG + veh group (dashed line, a replot from Figure 6a), challenge injection of CLG + PRX caused hypothermia in the MIO group. ${ }^{*} P<0.05,{ }^{* *} P<0.01$, and ${ }^{*}{ }^{* *} P<0.00$ I vs the $\mathrm{MIO}+\mathrm{CLG}+\mathrm{SAL}$ group. (c) Rats received either daily SAL ( $\mathrm{ml} / \mathrm{kg}$, s.c.; $N=4)$ or daily CLG $(2 \mathrm{mg} / \mathrm{kg}$, s.c.; $N=8)$ for 3 days and were examined on day 4. MK-80I (MK) at $0.25 \mathrm{mg} / \mathrm{kg}$ had no effect on $T_{\text {cor }}$ in rats in either SAL-pretreated or CLG-pretreated group. (d) All rats received daily CLG for 3 days and were examined on day 4. MK80I $(N=5)$ blocked the CLG + PRX-induced hyperthermia. Compared with the control (MK+CLG+SAL) group, challenge of $C L G+P R X$ caused hypothermia. ${ }^{*} P<0.05,{ }^{* *} P<0.01$ vs control $(M K+C L G+S A L)$ group.

displays overall changes of $T_{\text {cor }}$ in a PRX dose-dependent manner.

M100907 was used to evaluate the involvement of $5-\mathrm{HT}_{2 \mathrm{~A}}$ receptors in hyperthermia. Compared with the baseline, $2 \mathrm{mg} / \mathrm{kg} \mathrm{M100907} \mathrm{had} \mathrm{no} \mathrm{effect} \mathrm{on} T_{\text {cor }}$ in rats pretreated with SAL for 3 days but produced a reduction in CLGpretreated rats (Figure 6a). The one-way ANOVA analysis demonstrated a significant main effect of M100907 between SAL and CLG pretreatments $\left(\mathrm{F}_{(1,8)}=108.937, P<0.0001\right)$, suggesting that CLG pretreatment for 3 days was likely able to upregulate the functional activity of $5-\mathrm{HT}_{2 \mathrm{~A}}$ receptors.
This functional upregulation hypothesis was validated in a confirmatory study using the $5-\mathrm{HT}_{2 \mathrm{~A} / \mathrm{C}}$ receptor agonist DOI and followed by the 5- $\mathrm{HT}_{2 \mathrm{~A}}$ receptor antagonist M100907 (see details in Supplementary Figure S2). Next, M100907 was given 30 min before challenge injection of CLG + PRX. As shown in Figure 6b, M100907 not only blocked the hyperthermia induced by CLG + PRX but also caused a further reduction in $T_{\text {cor }}$ (hypothermia). Compared with the $\mathrm{M} 10+\mathrm{CLG}+\mathrm{SAL}$ group, the reduction was significantly greater (Figure $6 \mathrm{~b}, \mathrm{~F}_{(1,10)}=30.088, P=0.0003$ ). Lastly, MK801 was used to test the role of NMDA receptors. Unlike M100907, injection of $0.25-\mathrm{mg} / \mathrm{kg} \mathrm{MK}-801$ alone had no significant effect on $T_{\text {cor }}$ in CLG-pretreated rats (Figure 6c; $\left.\mathrm{F}_{(1,10)}=2.585, P=0.139\right)$. This suggests that CLG pretreatment for 3 days was unlikely able to alter basal activity of NMDA receptors. Despite this, the hyperthermic response to CLG + PRX was effectively blocked by MK-801, injected 30 min before the CLG + PRX challenge (Fig 6d; $F_{(1,7)}=$ $11.179, P=0.0124)$. There was a significant hypothermic effect as compared with the $\mathrm{MK}+\mathrm{CLG}+\mathrm{SAL}$ group $\left(\mathrm{F}_{(1,11)}=6.227, P=0.0298\right)$.

\section{Experiment 4: Syndrome Intensity Estimated by EEG}

Figure 7a depicts a set of raw EEG traces recorded in drug-naive rats in response to injection of $\mathrm{SAL}+\mathrm{PRX}$ or CLG + PRX. Injection of SAL + PRX had no apparent effect on EEG waves. In contrast, $\mathrm{CLG}+\mathrm{PRX}$ produced sudden bursts of electrical activity (spikes) characterized by low frequency $(\sim 2 \mathrm{~Hz})$ and high amplitude, which synchronized with the occurrences of head shakes. Note that the time of occurrence of a burst was very irregular and could not be anticipated. In this study, numbers of EEG bursts in the time frame of 0-60 min were manually counted and then displayed in bar graphs to reveal numbers of head shakes. Statistical analysis indicates that CLG + PRX caused a significant increase in numbers of head shakes (unpaired $t$-test, $t=6.205, P=0.0002$ ).

To determine whether the intensity of head shaking behavior depended on pre-exposure to 5-HT-promoting drugs, EEG recording was carried out on days 4, 7, and 14 in rats receiving daily CLG injection for 3, 6, and 13 days, respectively. Control groups were treated with saline (SAL; $0.9 \% \mathrm{NaCl}$ at $1 \mathrm{ml} / \mathrm{kg}$, once daily) on the same schedule. As shown in Figure 7b, challenge injection of CLG + PRX caused increases in EEG bursts of all groups. Days of CLG pretreatment had no significant effect on numbers of EEG bursts $\left(\mathrm{F}_{(3,19)}=0.992, P=0.4191\right)$.

Figure 8a displays effect of PRX doses on EEG bursts. Compared with the control, injection of CLG + PRX at the PRX doses of 1,5 , and $15 \mathrm{mg} / \mathrm{kg}$ caused significant increases in EEG bursts $\left(\mathrm{F}_{(3,23)}=12.393, P<0.0001\right)$. However, there was no significant difference among three PRX doses $(P>0.05)$.

M100907 and MK-801 were used to determine the possible involvement of $5-\mathrm{HT}_{2 \mathrm{~A}}$ and NMDA receptors, respectively, in EEG bursts. In this investigation, $2 \mathrm{mg} / \mathrm{kg}$ M100907 or $0.25 \mathrm{mg} / \mathrm{kg} \mathrm{MK}-801$ was injected $30 \mathrm{~min}$ before challenge of $2 \mathrm{mg} / \mathrm{kg}$ CLG combined with $15 \mathrm{mg} / \mathrm{kg}$ PRX in rats receiving daily CLG for 3 days. Control animals, which had also been treated with daily CLG for 3 days, were 
a

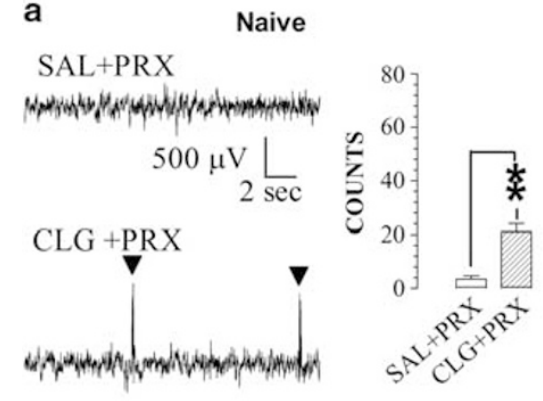

b

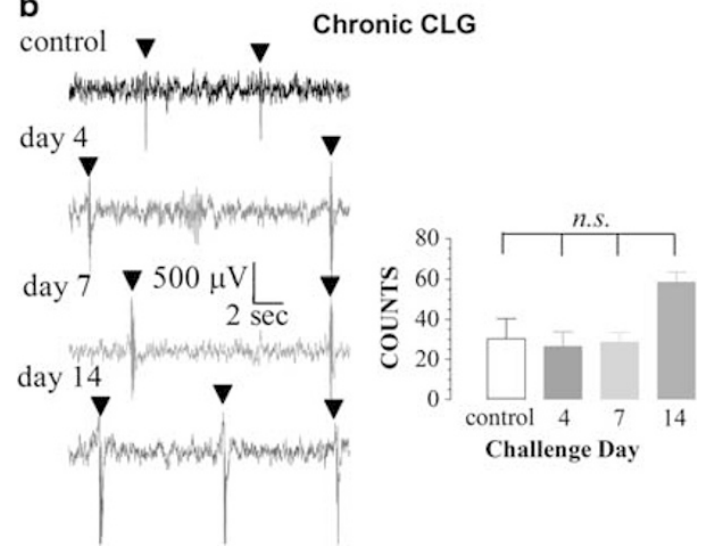

Figure 7 EEG bursts induced by a drug interaction between paroxetine (PRX; $15 \mathrm{mg} / \mathrm{kg}$, i.p.) and clorgyline (CLG; $2 \mathrm{mg} / \mathrm{kg}$, s.c.). Triangles ( $\mathbf{\nabla})$ indicate EEG bursts corresponding to head shaking behavior. Data are expressed as mean ( \pm SEM) counts of bursts. (a) Drug-naive rats. Left panel represents raw EEG traces ( $15 \mathrm{~s}$ each) clipped from the time frame of 0-60 min after drug injection, whereas right panel shows numbers of EEG bursts. PRX alone $(I 5 \mathrm{mg} / \mathrm{kg} ; \mathrm{N}=7)$ had no effect on EEG bursts. Challenge injection of CLG +PRX $(N=4)$ caused significant increases in EEG bursts: ${ }^{* *} P<0.0$ I. (b) Experimental animals were pretreated with daily CLG $(2 \mathrm{mg} / \mathrm{kg})$ for 3, 6, or 13 days and were challenged on days 4, 7, or I4 with CLG + PRX with the $P R X$ dose at $15 \mathrm{mg} / \mathrm{kg}(\mathrm{N}=5-7)$. Control animals were also challenged with $C L G+P R X$. Although challenge injection of CLG + PRX produced increases in EEG bursts in the control group and CLG pretreatment groups, there was no significant difference among them $(P>0.05$, n.s.).

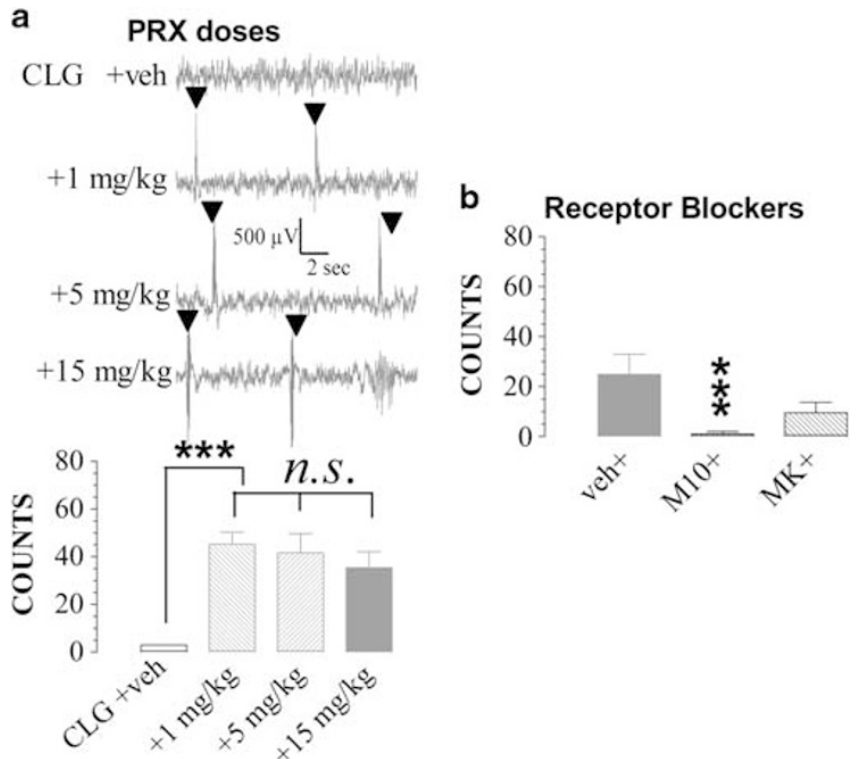

Figure 8 Paroxetine (PRX) dose-dependent changes in EEG bursts of rats pretreated with clorgyline (CLG, $2 \mathrm{mg} / \mathrm{kg}$, s.c.) once daily for 3 days. Experiments were carried out on day 4. Data are expressed as mean ( \pm SEM) counts of bursts. (a) The top panel shows an example of raw EEG traces and the bar graph in the bottom panel displays numbers of EEG bursts in the time frame of 0-60 min after challenge injection. Rats were challenged with CLG + PRC at the PRX doses of I $\mathrm{mg} / \mathrm{kg}(\mathrm{N}=9)$ or $5 \mathrm{mg} /$ $\mathrm{kg}(\mathrm{N}=7)$. Note that the $15-\mathrm{mg} / \mathrm{kg}$ data are a replot of Figure $7 \mathrm{~b}$. Although challenge injection of CLG + PRX produced increases in EEG bursts $\left({ }^{* * * *} P<0.00 \mathrm{I}\right)$, there was no dose-dependent difference among PRX doses $(P>0.05, n . s)$. (b) Animals were injected with vehicle (veh group; $N=6$ ), $2 \mathrm{mg} / \mathrm{kg}$ MIO0907 (MIO group; N=7), or 0.25 mg/kg MK-80I (MK group; $N=4), 30$ min before challenge injection of $C L G+P R X$ with the PRX dose at $15 \mathrm{mg} / \mathrm{kg}$. Compared with vehicle control, MI 00907 but not MK801 blocked increases in EEG bursts. ${ }^{* * * *} P<0.001$ vs control (veh + CLG+PRX) group.

injected with vehicle before the CLG + PRX challenge. As shown in Figure 8b, M100907 but not MK-801 significantly attenuated the effect $(P<0.001)$.

\section{DISCUSSION}

Possible induction of serotonin syndrome caused by serotonergic drugs (for example, MAOI and SSRI) has often been reported (Bucaretchi et al, 2009; Morrison and Rowe, 2012; Nelson and Philbrick, 2012; Pearce et al, 2009; Pedavally et al, 2013). The syndrome intensity is also discussed (Weiler et al, 2013). However, neural mechanisms underlying syndrome induction and intensity are rarely investigated. Thus, many knowledge gaps remain unanswered, including why the syndrome is mild in some cases but life-threatening in others, and what factors are there to determine the intensity level. Here, we demonstrated that a syndrome was elicited when 5-HT efflux was elevated multifold above baseline. In addition, compared with a mild syndrome in drug-naive controls, animals pretreated daily with the MAOI CLG for 3-6 days had an intensified syndrome in response to CLG + PRX, suggesting that a preexposure to serotoninergic drugs is, at least in part, responsible for the intensification of syndrome severity. Findings that blocking $5-\mathrm{HT}_{2 \mathrm{~A}}$ and NMDA receptors attenuated the syndrome intensity suggest that neural circuits containing these two receptors had been functionally upregulated and thereafter become more susceptible to drug adverse interaction. Thus, it is likely that the syndrome induction and subsequently the syndrome intensity involve two different sets of neural mechanisms. Accordingly, the syndrome can be induced or initiated when 5-HT efflux in response to 5-HT-promoting drugs exceeds a tolerable limit in the brain (presynaptic mechanisms). In contrast, the syndrome intensity may be mild, moderate, or severe, depending on responsivity of postsynaptic $5-\mathrm{HT}_{2 \mathrm{~A}}$ and NMDA receptors in neural circuits (postsynaptic mechanism). The concept of two mechanisms is novel, likely aiding our understanding of the diverse clinical presentation of serotonin syndrome.

We demonstrated that, in line with previous reports ( $\mathrm{Ma}$ et al, 2005; Shioda et al, 2004; Zhang et al, 2009), drug-todrug interaction caused to a great extent the increase in 5HT efflux. In this regard, it is important to determine at 
what level 5-HT efflux starts to induce a syndrome. It is believed that a small increase in 5-HT - for instance, $1 \sim 5$-fold greater than the basal level (Rutter and Auerbach, 1993) - is sufficient to exert its impact on neural circuits, mechanisms of which are considered to be the neural basis for treating depressive disorder and other mental disease (Tondo et al, 2013). In the present study, we showed that the minimum PRX dose that could induce obvious symptoms of serotonin syndrome was $5 \mathrm{mg} / \mathrm{kg}$ (Figure 3a), by which 5 -HT efflux was $\sim 10$-fold above baseline in the PFC or 13-fold in the POA (Figure 1c). Although $1 \mathrm{mg} / \mathrm{kg}$ PRX at which 5-HT efflux was approximately five- to sixfold above baseline could cause head shaking responses (Figure 7), other signs indicative of syndrome occurrence were absent (Figure 3a). Altogether, our studies suggest that, under our experimental conditions, even with the interaction with MAOI, the minimum therapeutic SSRI doses could not cause symptoms of the syndrome. Importantly, the central nervous system could well tolerate excessive 5-HT up to 10fold elevation. However, when the maximum therapeutic dose or overdose is given, the interaction may induce the syndrome in which 5-HT exceeds the baseline by more than 10-fold.

Although the CLG-PRX interaction at the PRX dose of $15 \mathrm{mg} / \mathrm{kg}$ injected into drug-naive rats could cause an $\sim 60-$ 80 fold increase in 5-HT efflux (Figure 1), the syndrome intensity was very mild (Figure 2). The data support our hypothesis that excessive $5 \mathrm{HT}$, which is critical for the syndrome induction, does not determine the syndrome intensity. One may argue that the intensity might be further intensified by increasing PRX doses. In this regard, we examined PRX doses up to $30 \mathrm{mg} / \mathrm{kg}$ combined with CLG and found no intensified syndrome in drug-native animals (data not shown). To further validate our findings and strengthen the conclusion, we also measured changes in $T_{\text {cor }}$, a simple and powerful approach for estimating the syndrome intensity. It was found that injection of CLG + PRX could cause only hypothermia but never hyperthermia in drug-native animals (Figure 4a). Since hypothermia is the sign of mild syndrome (Ma et al, 2008), these $T_{\text {cor }}$ results together with neuromuscular data support the conclusion that drug-naive animals in response to the CLG-PRX interaction could only have the mild syndrome, despite a very high level of excessive 5-HT in the brain, consistent with our hypothesis that excessive 5-HT level dissociate with syndrome intensity.

However, several studies demonstrated that drug-naive animals could develop a severe form of syndrome (Ma et al, 2008; Nisijima et al, 2001; Shioda et al, 2004). The discrepancy between this study and previous works may be attributed to the property of serotonergic drugs used to induce a syndrome. For many years, preclinical investigations into serotonin syndrome have been mainly based on 5-HTP combined with MAOI. 5-HTP is known as the 5-HT precursor but is not prescribed for medical uses except for a supplement (Turner et al, 2006). Whether the 5-HTPinduced syndrome is relevant to clinical case has been questioned (Isbister and Buckley, 2005; Ma et al, 2013). For instance, the syndrome induced by 5-HTP is manifested by a rapid onset and high mortality. In contrast, a syndrome in human patients usually has a slow onset and lasts for many hours or days (Boyer and Shannon, 2005). In addition to
5-HTP, 8-OH-DPAT is another potent drug often used for investigating symptoms of serotonin syndrome (Darmani and Zhao, 1998). Despite neuromuscular hyperactivity, 8-OH-DPAT does not impair autonomic function commonly manifested in the syndrome in human patients (Bucaretchi et al, 2009; Pearce et al, 2009). Thus, the syndrome produced by 8 -OH-DPAT unlikely fully reveals mechanisms relevant to human cases. For these reasons, the syndrome induced by CLG + PRX in this study would be most appropriate for understanding the mechanisms relevant to clinical cases.

We showed that daily CLG pretreatments for consecutive 3-6 days intensified neuromuscular hyperactivity and induced hyperthermia, indicating that the syndrome intensity depends on duration of previous serotonergic pretreatment. At first glance, the intensified response is likely attributed to chronic CLG-induced augmentation in serotonergic neuronal activity, consistent with the working hypothesis proposed in literature (Stanford et al, 2010). Our data showed that the basal 5-HT level was significantly increased in a time-dependent manner in response to CLG pretreatments (see details in Results). However, after an abroad analysis of relationship between the syndrome intensity and excessive 5-HT (Figure 1b and Supplementary Figure S1), we found that the syndrome intensity was not proportional to changes in 5-HT efflux, arguing against the involvement of excessive 5-HT in the syndrome intensification.

Our data showed that the $5-\mathrm{HT}_{2 \mathrm{~A}}$ receptor antagonist M100907 significantly blocked the increased behavioral score and hyperthermia in CLG-pretreated rats. This suggests that increased intensity of the syndrome may be associated with responsivity of $5-\mathrm{HT}_{2 \mathrm{~A}}$ receptors. However, little was known about how CLG pretreatment affects $5-\mathrm{HT}_{2 \mathrm{~A}}$ receptor activity. We propose that CLG pretreatment had caused functional upregulation of $5-\mathrm{HT}_{2 \mathrm{~A}}$ receptors. This upregulation hypothesis is consistent with previous reports that chronic serotonergic treatments could sensitize $5-\mathrm{HT}_{2 \mathrm{~A}}$ receptors in the brain (Cai et al, 2013; Freo et al, 2010). The upregulation likely changes tonic activity of $5-\mathrm{HT}_{2 \mathrm{~A}}$ receptors that are normally known to control bodycore temperature or $T_{\text {cor }}$ (Lin et al, 1998). Consistent with the hypothesis, we found that hyperthermic response in CLG-pretreated rats was attenuated by the $5-\mathrm{HT}_{2 \mathrm{~A}}$ receptor antagonist M100907 (Figure 6a). To further validate the upregulation hypothesis, we carried out a supplementary study using the $5-\mathrm{HT}_{2 \mathrm{~A} / \mathrm{C}}$ receptor agonist DOI and followed by the $5-\mathrm{HT}_{2 \mathrm{~A}}$ receptor antagonist M100907 (Supplementary Figure S2). Together, our data suggest that the $5-\mathrm{HT}_{2 \mathrm{~A}}$ receptor upregulation may be the main mechanism underlying the intensified response to excessive 5-HT. This is in line with the general framework demonstrating that $5-\mathrm{HT}_{2 \mathrm{~A}}$ receptors are the key mediator for the development of severe and malignant syndrome (Ma et al, 2008; Nisijima et al, 2001).

$5-\mathrm{HT}_{2 \mathrm{~A}}$ receptors are widely distributed in the CNS (Bombardi, 2011; Cornea-Hebert et al, 1999; Fedeli et al, 2002). Further studies revealed that $5-\mathrm{HT}_{2 \mathrm{~A}}$ receptors are mainly localized on glutamatergic neurons in the forebrain and integrated with neural circuits between raphe midbrain and forebrain for controlling glutamate and 5-HT release responsible for schizophrenic diseases (Aghajanian and 
Marek, 1999; Bortolozzi et al, 2003). We found previously that this circuit may also mediate serotonin syndrome as demonstrated by acute injection of 5-HTP combined with CLG (Ma et al, 2008; Zhang et al, 2009). In the present study, the NMDA receptor blocker MK-801 significantly attenuated the increased behavioral score and autonomic dysfunction (ie, hyperthermia), suggesting that NMDA receptors and NMDA receptor-engaged circuits might be involved in the exacerbation of syndrome intensity after long-term exposure to CLG. Additional studies are underway to evaluate the distinct functions of each receptor in the exacerbated response. One clue supports the leading role of $5-\mathrm{HT}_{2 \mathrm{~A}}$ receptors that M100907 could block the entire portion of exacerbated response in behavioral scores and autonomic dysfunction, whereas the antagonistic role of the NMDA receptor antagonist MK-801 was relatively partial in some of these effects. Considering the fact that serotonin syndrome is primarily initiated by excessive 5 -HT efflux, it is conceivable that activation of $5-\mathrm{HT}_{2 \mathrm{~A}}$ receptors may exert a permissive role in exacerbating the syndrome intensity.

Unexpectedly, the syndrome intensity examined on day 14 in rats with daily CLG pretreatments for 13 days was no longer intensified. Rather, it was significantly abated to a mild level similar to that of drug-naive control. The simplest explanation for such cutback in intensity is that enhanced responsivity of $5-\mathrm{HT}_{2 \mathrm{~A}}$ receptors induced on the early days of CLG pretreatment (for example, before day 7) might return to normal sensitivity in spite of continuum of CLG pretreatments. However, other factors ought to be considered. For instance, it has been suggested that, in addition to $5-\mathrm{HT}_{2 \mathrm{~A}}$ receptors, chronic serotonergic antidepressant treatments can influence activity of many, if not all, subtypes of 5-HT receptors and some of non-5-HT receptors (Barbon et al, 2011; Vidal et al, 2013). As the time course in modulating these individual receptors may be different, it can be speculated that the functionality of $5-\mathrm{HT}_{2 \mathrm{~A}}$ receptors might be compromised as some other receptor modulations are later emerged into action. We also noted that 5-HT response to CLG + PRX was dramatically reduced to 10 -fold relative to baseline, barely reaching the threshold for inducing a syndrome. Although such reduction had to some extent an effect on syndrome intensity, it could not serve as evidence for interpreting why the syndrome intensity was reduced on day 14 because the absolute efflux of 5-HT was not altered (Supplementary Fig. S1). Therefore, further experiments are needed to clarify this issue.

Head shaking behavior has been considered to be an early warning sign indicative of serotonin syndrome (Darmani and Ahmad, 1999; Ma et al, 2008), and thus was included into the present investigation. Indeed, we found that onset of head shakes or EEG bursts started as early as 5 min after challenge injection of CLG + PRX. The rapid onset is similar to that observed in our previous study with 5-HTP combined with CLG examined in drug-naive animals (Ma et al, 2008). It appears that changes in head shaking behavior were more remarkable than other behaviors. It is believed that head shakes are associated with $5-\mathrm{HT}_{2 \mathrm{~A}}$ receptor activation (Garcia et al, 2007; Matuszewich and Yamamoto, 2003). In the present study, findings that EEG bursts reflecting head shakes were significantly blocked by the $5-\mathrm{HT}_{2 \mathrm{~A}}$ receptor antagonist M100907 are in line with the
5- $\mathrm{HT}_{2 \mathrm{~A}}$ receptor activation hypothesis. In contrast, the NMDA receptor antagonist MK-801 could not significantly antagonize the head shaking response, suggesting that NMDA receptors are not a part of neural circuit components mediating this particular behavior. We noticed that CLG pretreatments failed to intensify the head shaking behavior (Figure $7 \mathrm{~b}$ ) and PRX injection failed to produce a dose-dependent response (Figure 8a). In this regard, the findings are not entirely consistent with the postsynaptic hypothesis. It is likely that head shaking behavior is exquisitely sensitive to excessive 5 -HT, and that a nearmaximum effect had been induced regardless of CLG pretreatments or increasing PRX doses. There are many studies demonstrating that the head shaking behavior may be indicative of serious emotional disturbance (Marek, 2009; Vickers et al, 2001; Yamada et al, 1995). Our findings could have implications that mental health in the syndrome is more vulnerable to excessive 5-HT than neuromuscular or autonomic disorders.

In summary, the present study indicates that the intensity of serotonin syndrome is determined by not simply drug doses, but medical history, particularly a time frame of previous serotonergic drug use. This may be attributed to postsynaptic mechanisms in which previous serotonergic drugs have functionally upregulated postsynaptic $5-\mathrm{HT}_{2 \mathrm{~A}}$ receptors and relevant neural circuits, and thereafter promoting the adverse response to excessive 5-HT. With this knowledge, the syndrome may be better managed. In addition, we showed that challenge injection of CLG + PRX following CLG pretreatment is a novel animal model of clinically relevant serotonin syndrome, essential for future investigation of neural mechanisms responsible for unwanted side effects.

\section{FUNDING AND DISCLOSURE}

The authors declare no conflict of interest.

\section{ACKNOWLEDGEMENTS}

This work was supported by NIH grand (R15DA029863) and Florida Atlantic University Undergraduate Research Grant (M30023). We would like to thank the National Institute on Drug Abuse (Rockville, MD) for providing M100907 to this investigation. We are grateful to Dr Ibrahim M. Shokry for his helpful comments on the manuscript.

\section{REFERENCES}

Aghajanian GK, Marek GJ (1999). Serotonin, via 5- $\mathrm{HT}_{2 \mathrm{~A}}$ receptors, increases EPSCs in layer $\mathrm{V}$ pyramidal cells of prefrontal cortex by an asynchronous mode of glutamate release. Brain Res 825: 161-171.

Barbon A, Caracciolo L, Orlandi C, Musazzi L, Mallei A, La Via L et al (2011). Chronic antidepressant treatments induce a timedependent up-regulation of AMPA receptor subunit protein levels. Neurochem Int 59: 896-905.

Beyer CE, Boikess S, Luo B, Dawson LA (2002). Comparison of the effects of antidepressants on norepinephrine and serotonin concentrations in the rat frontal cortex: an in-vivo microdialysis study. J Psychopharmacol 16: 297-304. 
Bombardi C (2011). Distribution of $5-\mathrm{HT}_{2 \mathrm{~A}}$ receptor immunoreactivity in the rat amygdaloid complex and colocalization with gamma-aminobutyric acid. Brain Res 1370: 112-128.

Bortolozzi A, Amargos-Bosch M, Adell A, Diaz-Mataix L, Serrats J, Pons $S$ et al (2003). In vivo modulation of 5-hydroxytryptamine release in mouse prefrontal cortex by local $5-\mathrm{HT}_{2 \mathrm{~A}}$ receptors: effect of antipsychotic drugs. Eur J Neurosci 18: 1235-1246.

Boyer EW, Shannon M (2005). The serotonin syndrome. N Engl J Med 352: 1112-1120.

Bucaretchi F, de Capitani EM, Mello SM, Lanaro R, Barros RF, Fernandes LC et al (2009). Serotonin syndrome following sibutramine poisoning in a child, with sequential quantification of sibutramine and its primary and secondary amine metabolites in plasma. Clin Toxicol (Phila) 47: 598-601.

Cai X, Kallarackal AJ, Kvarta MD, Goluskin S, Gaylor K, Bailey AM et al (2013). Local potentiation of excitatory synapses by serotonin and its alteration in rodent models of depression. Nat Neurosci 16: 464-472.

Cornea-Hebert V, Riad M, Wu C, Singh SK, Descarries L (1999). Cellular and subcellular distribution of the serotonin $5-\mathrm{HT}_{2 \mathrm{~A}}$ receptor in the central nervous system of adult rat. J Comp Neurol 409: 187-209.

Darmani NA, Ahmad B (1999). Long-term sequential determination of behavioral ontogeny of $5-\mathrm{HT}_{1 \mathrm{~A}}$ and $5-\mathrm{HT}_{2}$ receptor functions in the rat. J Pharmacol Exp Ther 288: 247-253.

Darmani NA, Zhao W (1998). Production of serotonin syndrome by 8-OH-DPAT in Cryptotis parva. Physiol Behav 65: 327-331.

Fedeli A, Ciccocioppo R, Economidou D, Angeletti S, Massi M (2002). Autoradiographic analysis of 5-hydroxytryptamine $5-\mathrm{HT}_{2 \mathrm{~A}}$ binding sites in the rat brain after chronic intragastric ethanol treatments. Res Commun Mol Pathol Pharmacol 112: 113-127.

Finberg JP, Pacak K, Kopin IJ, Goldstein DS (1993). Chronic inhibition of monoamine oxidase type A increases noradrenaline release in rat frontal cortex. Naunyn Schmiedebergs Arch Pharmacol 347: 500-505.

Freo U, Merico A, Ermani M, Ori C (2010). Chronic treatment with fluoxetine decreases cerebral metabolic responses to the $5-\mathrm{HT}_{1 \mathrm{~A}}$ agonist 8-hydroxy-2(di-N-propylamino)tetralin and increases those to the 5- $\mathrm{HT}_{2 \mathrm{~A} / 2 \mathrm{C}}$ agonist 1-(2,5-dimethoxy-4-iodophenyl)-2-aminopropane and to the dopaminergic agonist apomorphine. Brain Res 1335: 24-34.

Garcia EE, Smith RL, Sanders-Bush E (2007). Role of $\mathrm{G}_{\mathrm{q}}$ protein in behavioral effects of the hallucinogenic drug 1-(2,5dimethoxy-4-iodophenyl)-2-aminopropane. Neuropharmacology 52: 1671-1677.

Grady MM, Stahl SM (2012). Practical guide for prescribing MAOIs: debunking myths and removing barriers. CNS Spectr 17: 2-10.

Isbister GK, Buckley NA (2005). The pathophysiology of serotonin toxicity in animals and humans: implications for diagnosis and treatment. Clin Neuropharmacol 28: 205-214.

Kreilgaard M, Smith DG, Brennum LT, Sanchez C (2008). Prediction of clinical response based on pharmacokinetic/ pharmacodynamic models of 5-hydroxytryptamine reuptake inhibitors in mice. Br J Pharmacol 155: 276-284.

Lin MT, Tsay HJ, Su WH, Chueh FY (1998). Changes in extracellular serotonin in rat hypothalamus affect thermoregulatory function. Am J Physiol 274: R1260-R1267.

Ma Z, Rudacille M, Prentice HM, Tao R (2013). Characterization of electroencephalographic and biochemical responses at 5-HT promoting drug-induced onset of serotonin syndrome in rats. J Neurochem 125: 774-789.

Ma Z, Strecker RE, McKenna JT, Thakkar MM, McCarley RW, Tao $\mathrm{R}$ (2005). Effects on serotonin of (-)nicotine and dimethylphenylpiperazinium in the dorsal raphe and nucleus accumbens of freely behaving rats. Neuroscience 135: 949-958.

Ma Z, Zhang G, Jenney C, Krishnamoorthy S, Tao R (2008). Characterization of serotonin-toxicity syndrome (toxidrome) elicited by 5 -hydroxy-l-tryptophan in clorgyline-pretreated rats. Eur J Pharmacol 588: 198-206.

Marek GJ (2009). Activation of adenosine $\mathrm{A}_{\mathrm{A} 1}$ receptors suppresses head shakes induced by a serotonergic hallucinogen in rats. Neuropharmacology 56: 1082-1087.

Mason PJ, Morris VA, Balcezak TJ (2000). Serotonin syndrome. Presentation of 2 cases and review of the literature. Medicine (Baltimore) 79: 201-209.

Matuszewich L, Yamamoto BK (2003). Long-lasting effects of chronic stress on DOI-induced hyperthermia in male rats. Psychopharmacology (Berl) 169: 169-175.

Meyer JH, Wilson AA, Sagrati S, Hussey D, Carella A, Potter WZ et al (2004). Serotonin transporter occupancy of five selective serotonin reuptake inhibitors at different doses: an $\left({ }^{11} \mathrm{C}\right] \mathrm{DASB}$ positron emission tomography study. Am J Psychiatry 161: 826-835.

Mitchell RS (1955). Fatal toxic encephalitis occurring during iproniazid therapy in pulmonary tuberculosis. Ann Intern Med 42: 417-424.

Morrison EK, Rowe AS (2012). Probable drug-drug interaction leading to serotonin syndrome in a patient treated with concomitant buspirone and linezolid in the setting of therapeutic hypothermia. J Clin Pharm Ther 37: 610-613.

Nelson EM, Philbrick AM (2012). Avoiding serotonin syndrome: the nature of the interaction between tramadol and selective serotonin reuptake inhibitors. Ann Pharmacother 46: 1712-1716.

Nelson LS, Erdman AR, Booze LL, Cobaugh DJ, Chyka PA, Woolf $\mathrm{AD}$ et al (2007). Selective serotonin reuptake inhibitor poisoning: an evidence-based consensus guideline for out-of-hospital management. Clin Toxicol (Phila) 45: 315-332.

Nisijima K, Yoshino T, Yui K, Katoh S (2001). Potent serotonin $\left(5-\mathrm{HT}_{2 \mathrm{~A}}\right)$ receptor antagonists completely prevent the development of hyperthermia in an animal model of the 5-HT syndrome. Brain Res 890: 23-31.

Paxinos G, Watson C (1998). The Rat Brain in Stereotaxic Coordinates. Academic Press: San Diego.

Pearce S, Ahned N, Varas GM (2009). A case study of delayed serotonin syndrome: lessons learned. Consult Pharm 24: 64-68.

Pedavally S, Fugate JE, Rabinstein AA (2013). Serotonin Syndrome in the Intensive Care Unit: Clinical Presentations and Precipitating Medications. Neurocrit Care doi:10.1007/s12028-013-9914-2.

Romero L, Bel N, Artigas F, de Montigny C, Blier P (1996). Effect of pindolol on the function of pre- and postsynaptic 5-HT1A receptors: in vivo microdialysis and electrophysiological studies in the rat brain. Neuropsychopharmacology 15: 349-360.

Ruhe HG, Booij J, v Weert HC, Reitsma JB, Franssen EJ, Michel MC et al (2009). Evidence why paroxetine dose escalation is not effective in major depressive disorder: a randomized controlled trial with assessment of serotonin transporter occupancy. Neuropsychopharmacology 34: 999-1010.

Rutter JJ, Auerbach SB (1993). Acute uptake inhibition increases extracellular serotonin in the rat forebrain. J Pharmacol Exp Ther 265: 1319-1324.

Shioda K, Nisijima K, Yoshino T, Kato S (2004). Extracellular serotonin, dopamine and glutamate levels are elevated in the hypothalamus in a serotonin syndrome animal model induced by tranylcypromine and fluoxetine. Prog Neuropsychopharmacol Biol Psychiatry 28: 633-640.

Stanford SC, Stanford BJ, Gillman PK (2010). Risk of severe serotonin toxicity following co-administration of methylene blue and serotonin reuptake inhibitors: an update on a case report of post-operative delirium. J Psychopharmacol 24: 1433-1438.

Sternbach H (2003). Serotonin syndrome: how to avoid, identify, and treat dangerous drug interaction. Current Psychiatry 2: $15-23$.

Tondo L, Baldessarini RJ, Vazquez G, Lepri B, Visioli C (2013). Clinical responses to antidepressants among 1036 acutely depressed patients with bipolar or unipolar major affective disorders. Acta Psychiatr Scand 127: 355-364. 
Turner EH, Loftis JM, Blackwell AD (2006). Serotonin a la carte: supplementation with the serotonin precursor 5-hydroxytryptophan. Pharmacol Ther 109: 325-338.

Vickers SP, Easton N, Malcolm CS, Allen NH, Porter RH, Bickerdike MJ et al (2001). Modulation of 5- $\mathrm{HT}_{2 \mathrm{~A}}$ receptormediated head-twitch behaviour in the rat by $5-\mathrm{HT}_{2 \mathrm{C}}$ receptor agonists. Pharmacol Biochem Behav 69: 643-652.

Vidal R, Diaz A, Pazos A, Castro E (2013). Region-specific regulation of $5-\mathrm{HT}_{1 \mathrm{~B}}$ receptors in the rat brain by chronic venlafaxine treatment. Psychopharmacology (Berl) 229: $177-185$.
Weiler S, Offinger A, Exadaktylos AK (2013). Shaking head means 'no'. BMJ Case Rep 2013: pii: bcr2013200796.

Woytowish MR, Maynor LM (2013). Clinical relevance of linezolidassociated serotonin toxicity. Ann Pharmacother 47: 388-397.

Yamada S, Watanabe A, Nankai M, Toru M (1995). Acute immobilization stress reduces \pm DOI-induced $5-\mathrm{HT}_{2 \mathrm{~A}}$ receptor-mediated head shakes in rats. Psychopharmacology (Berl) 119: 9-14.

Zhang G, Krishnamoorthy S, Ma Z, Vukovich NP, Huang X, Tao R (2009). Assessment of 5-hydroxytryptamine efflux in rat brain during a mild, moderate and severe serotonin-toxicity syndrome. Eur J Pharmacol 615: 66-75.

Supplementary Information accompanies the paper on the Neuropsychopharmacology website (http://www.nature.com/npp) 